\title{
A Review of Critical Discourse Analysis Studies in China
}

\author{
Jun Chen ${ }^{1, *}$, Lei Wang ${ }^{2}$ \\ ${ }^{1}$ School of Foreign Languages, Northwestern Polytechnical University, China \\ ${ }^{2}$ School of Liberal Arts, Xi' an International University, China
}

Copyright $\mathrm{O} 2016$ by authors, all rights reserved. Authors agree that this article remains permanently open access under the terms of the Creative Commons Attribution License 4.0 International License

\begin{abstract}
The paper provides a review of critical discourse analysis (CDA) studies in China from the 1990s. It starts with the origin, definition, and research scope of CDA in America and Europe. Although Chinese scholars began to show interest in CDA studies in 1995, about two decades later than their western counterparts, they have made considerable achievements in the field. On the review research level, quite a few independent studies indicate that CDA studies are attracting increasing attention from the field of linguistics, media studies, politics, and philosophy; theoretical and methodological research reveals that Chinese scholars are endeavoring to yield original research results on the basis of CDA studies abroad; practical research shows that CDA has been applied to the investigation of various discourses to disclose social reality, especially the inter-relationship between discourse, power and ideology.
\end{abstract}

Keywords Critical Discourse Analysis, Review Research, Theoretical and Methodological Research, Practical Research, Power, Ideology

\section{Introduction}

The term, "Discourse Analysis", was first proposed by American structural linguist Zellig Harris in his research article entitled Discourse Analysis in 1952. The famous British linguist Roger Fowler gave rise to the discipline of critical linguistics in his book Language and Control in 1979. In 1989, one of the founders of CDA, Fairclough, clarified its concept for the first time in his monograph Language and Power, which explored the imbrications between language and social institutional practices and of "wider" political and social structures. CDA was formally considered as a branch of discourse analysis and accepted by the linguistic field in 1991 when Kristen Malmkjer listed it as the counterpart of textual analysis and conversational analysis in The Linguistics Encyclopedia.

Before we define the term CDA, it is necessary for us to give a working definition or scope of the sub-term "discourse". Mills (1997: 2) [1], in her interpretation of discourse as a concept, figures out its broadest definition as simply "verbal communication." In more specific terms, discourse has been defined as "conversational talk, formal speech or writing on a particular subject, or a linguistic unit greater than one sentence, reflecting the origins of the word as a linguistic concept" (Leslie Burns \& Ernest Morrell, 2006: 54) [2]. As for one of the founding fathers of CDA, Fairclough (1992: 8) [3] commented that "Discourse constitutes the social reality. Three dimensions of the social are distinguished-knowledge, social relations, and social identity - and these correspond respectively to three major functions of language... Discourse is shaped by relations of power and invested with ideologies."

From the above interpretations of "discourse," it is clear that "discourse" is an extremely broad term involving both linguistic and social factors. It does not only include texts or words in written and spoken forms, but also penetrates into the relationship between language and power that constructs the social ideology.

The other term involved with CDA, "critical", must be understood along with discourse as it is closely related to "ideology." CDA construes discourses as ideological because they are used to represent the systems of thought, manifested in language that groups and individuals use to identify themselves, filter information, and interpret meaning. Within the scope of ideology, CDA asserts that an ideology is positive or negative depending on whether it helps to achieve some desirable goal in a desirable way; in other words, there is neither "good" nor "bad" ideology, and the only difference one treats the same discourse differently lies in the standpoints he/she holds. Thus, van Dijk (1998) [4]comments that "from a critical perspective some ideologies are 'better' than others when the social project involves an attempt to achieve equity".

Besides, there are other aspects of "critical". What is the difference between CDA and other means of discourse analysis? For the discourse analysis in the scope of linguistics, it largely focuses on the analysis of texts within the framework of text-linguistics, stylistics, rhetoric, etc, while for CDA, it places emphasis on the relationship between language and social change and intervention, and tries to explain who controls the power to speak in a given 
ideological context. In other words, "critical analysis" stresses properties of social interaction and especially social structure of a discourse. Therefore, it can be assumed that the subjectivity of any discourse is probably a relative concept in that the one who has the control over the power to speak has the final say about the issue concerned and therefore influences others' conception of the issue.

As for the concept of CDA, it is long considered as "an interdisciplinary approach to the study of discourse that views language as a form of social practice and focuses on the ways social and political domination are reproduced in text and talk" (Fairclough \& Clive: 1995) [5]. Fairclough further developed a three-dimensional framework for studying discourse from a critical perspective, where three separate forms of analysis are mapped onto one another: analysis of (spoken or written) language texts, analysis of discourse practice (processes of text production, distribution and consumption) and analysis of discursive events as instances of socio-cultural practice (Fairclough: 2001) [6].

Similarly, Teun A. van Dijk defined CDA as "a type of discourse analytical research that primarily studies the way social power abuse, dominance and inequality are enacted, reproduced and resisted by text and talk in the social and political context" (van Dijk: 1999) [7]. With such dissident research, critical discourse analysts take explicit position, and thus want to understand, expose and ultimately to resist social inequality.

So far, CDA has already become an interdisciplinary principle, which draws essence from linguistics, anthropology, psychology, politics, mass communication, philosophy and so forth to examine ideologies and power relations involved in the discourse. And its representatives include Fowler, Norman Fairclough, Dan Karreman, and Teun A. van Dijk.

CDA has made much process since 1970s in the international community. However, CDA studies in China did not begin until Chen (1995) [8] introduced critical linguistics in 1995. Since then, academic research has attracted considerable attention in the linguistic circle and plentiful accomplishments have been achieved.

\section{Review Research}

Lan and Wang (2010) [9] reviewed major CDA studies in China from June, 2005 to December, 2009 by analyzing all related research articles in eleven key linguistic journals and made their own discoveries and conclusions.

Altogether, 53 research articles that are representative and authoritative serve as the samples for their discussion. Their major findings are listed as follows: (1) Although there appeared only two articles in the second half of 2005, the enthusiasm in CDA surged from 2006. And 2009 witnessed 31 high-quality articles in the field, which indicates that CDA began to attract increasing attention in the domestic academic circle. (2) Academic linguistics journals placed amounting emphasis on CDA studies. For example, Foreign
Language Research established a research column for CDA in the June Issue in 2008, which offered CDA a favorable atmosphere for development. (3) The number of researchers concentrating on CDA studies was on the rise. 49 authors contributed to these 53 articles. (4) CDA studies at the time mainly focused on the introduction and induction of research findings in the international academic community. Articles on theoretical introduction and review studies took up the overwhelming majority. Few articles analyzed specific discourse or text. (5) Comparative critical analysis between Chinese discourse and English discourse emerged and Prof. $\mathrm{Xin}$, the most prominent in this aspect, analyzed and compared modes and sources of reported speech in China Daily and The New York Times. However, it is a pity that no other scholars made similar attempts. (6) In the aspect of research methodologies, there were more articles on theoretical research than on practical research in these five years. Yet, it should be noted that the number of articles on practical investigations surpassed those on theoretical review in the year 2009 and the trend continues.

Although Chinese scholars have made great achievements in the field of CDA studies, limitations still exist. First of all, the extent and layers of CDA studies abroad have been extended to political discourse, ideology, racial studies, migrant studies, media language, institutional discourse, social discourse, bureaucratic discourse and so forth. Instead, domestic studies still stress the review of foreign research findings. Some current studies at home involve institutional discourse, legal discourse and advertising discourse, but these studies are not in-depth enough to analyze the inner mechanism of the discourse critically. In the second place, the research content of CDA studies at home is confined to a limited scope because Chinese scholars started to investigate CDA relatively late. Over half of the selected articles are about introduction of CDA theories aboard. Even when there is discussion on sensitive topics of political and medium issues, the materials for discussion are of foreign origin instead of Chinese materials. Lan and Wang's review studies have indicated that the focus on CDA studies in China has been shifting from theoretical investigation to application of CDA theories to the analysis of specific discourse in diverse social contexts.

By reviewing the background, methodology and current development of CDA studies, $\mathrm{Li}$ (2004) [10] put forward his perspectives of CDA in practical discourse analysis and language teaching in several aspects. On the one hand, the presumption of CDA lies in that discourse is a social factor that contributes constructively to social transformation. Therefore, Fariclough maintains that critical analysis can promote social progress. Domestic scholars have applied the tool of CDA to the analysis of social discourse to investigate the relationship between discourse and society. For example, Yuan (2001) [11] pointed out that critical analysis of political discourse is aimed at investigating the social functions of discourse and socio-cultural factors that are presented in the discourse. Jiang (2003) [12] further revealed the implicit ideology and power relations in language by 
analyzing English news and pointed out that the international media overwhelmed with English news influenced and even dominated world audience's ideology. So it is of great significance to disclose the implicit relations between discourse and ideology to clarify how powerful classes control and maintain their authorities by employing language as a means of ideology control.

Review research about CDA has outlined the current trend of CDA studies in China and has given hints on foreign language teachers how to expose the political and social inclination of news reports about Chinese issues in some foreign mass media. With the comprehensive development of economy of China and the fast-paced globalization in recent years, western mass media begin to penetrate into Chinese domestic market. Thus, it is necessary for Chinese readers to raise their awareness of power relations and ideology in news discourse to promote their understanding of news discourse critically. In a similar way, our foreign language teaching is not supposed to be an isolated tool to teach language to students. Instead, more social factors can be considered in language teaching to cultivate students to know the importance of ideology in political and social life.

\section{Theoretical and Methodological Research}

The review studies on CDA studies at home by Lan \& Wang (2010) and Li (2001) have offered us a macro picture of how CDA developed in the decade of 2000 to 2009. For this section and the section that follows, details of theoretical and methodological research and practical research on CDA studies in China is to be presented.

Mainstream theories and methodologies in CDA are of the foreign origin, as is illustrated in the previous sections. As a result, research on CDA at home is primarily on the application of CDA to the analysis of language materials, so only a few theoretical and methodological studies contribute to $\mathrm{CDA}$.

Xin (1996) [13] comprehensively reviewed major theoretical achievements of CDA studies abroad in 1980s and 1990s and the major findings are as follows: (1) Fowler's Language and Control (1979) is served as the cornerstone for critical linguistics in that it reveals the influence that ideology exerts on discourse and the interaction between social structure and power relations. He criticized the former discourse studies that neglected the connection between language and society and pointed out that discourse studies should focus on the descriptive aspect of language and answer questions concerning "why" and "how"; (2) Halliday's functional grammar stresses the importance of social context of language and offers practical tools to analyze discourse critically; (3) Fairclough focuses on how ideology influences language practice and how language is controlled by the powerful social class to spread their ideology. By using the above theories, Xin (1997)[14] did an analytical research on English discourse from aspects of classification, transitivity, modality and transformation, concentrating on the ideological traits that exist in English discourse. Besides, by noting that linguists are supposed to emphasize the social functions of language, Xin (2000) [15] established a general method for the CDA studies of English news discourse. He highly recommended comparative methods in CDA of news discourse in the following three aspects: (1) compare semantic functions of some linguistic structures and expressions in English news discourse; (2) analyze the news reports on the same issue from different news agencies to explore the subtle differences in standpoints; (3) analyze the successive news reports on one issue from the same agency to investigate whether there is a change of reporter's viewpoints. Xin (2002) [16] further summarized CDA methodologies: the general methodology takes SFG as its primary theoretical foundation and source; the methodologicalframework of depth hermeneutics proposed by Thompson analyzes the discourse ideology from three aspects: social-historical, formal or discursive analysis and interpretation/ re-interpretation.

Xin (2004) [17] took Stubbs's eleven questions concerning CDA studies as a clue to present his viewpoints on the criticism on CDA. In general, as a tool in discourse analysis, $\mathrm{CDA}$ is still in the process of developing due to its prematurity and its advocates as well as practitioners have realized its limitations. Some of the criticism towards CDA studies appears to be too tough which indicates that critics have expects too much from CDA. So far, most scholars in CDA field have accepted the following five points: (1) analysts cannot reasonably explain the intuitional comprehension of discourse without abundant linguistic and pragmatic knowledge; (2) the more linguistic and pragmatic knowledge analysts have mastered, the more explicitly and deeply they explore the communicative effects that discourse has created; (3) conclusions were draw from the analysis of language structures of discourse need to be supported or verified by analysis results of other aspects of the discourse; (4) analysts' evidence to interpret and illustrate discourse and ways of drawing conclusions must be clear enough for others to examine the research results with the same method; (5) analysts themselves must understand that their analysis results or conclusions tend to change with the changes of context or information flow.

Ji (2001) [18] reviewed three methods of CDA. Besides the systemic-function analysis that is familiar to us, there is also inter-textual analysis and historical analysis, which can complement traditional methods of social and cultural analysis. Inter-textual analysis values the productivity and creativity of discourse analysis which originates from the peculiarity of texts or inter-textuality. It analyzes the rhetoric intentions in the author's production of texts and readers' comprehension of these intentions. Dai and Chen (2004) [19] carried out a similar study and discussed the influence of ideology on the production of online news.

Li and Zhang (2007) [20] sketched a general situation of CDA from its origins, theories, contents and achievements and predicted the difficulties to face in CDA studies. Like 
other aspects in social studies, CDA is confronted with a tough situation that its research subjects are constantly changing and the diverse values and perceptions from different multinational institutions and social organizations along with the change bring about new challenges of how to analyze the discourse deriving from the changes critically.

Zhang (2009) [21] established a synthetic theoretical framework for multimodal discourse analysis on the basis of systemic functional linguistics. The framework mainly consists of multimodal discourse systems at five levels: (1) The level of context of culture, (2) the level of context of situation, (3) the semantic level, (4) the formal level and (5) the level of media (substance). He put forward the relationship among the image grammar units (member, figure, episode), their grammatical structures and discourse structures and pointed out that various non-lingual media, especially modern media technologies, offer abundant choices for discourse communication.

In general, theoretical and methodological CDA studies in China mainly follow the way of European scholars and few new theories and methodologies have been proposed. However, Chinese scholars in the field have adapted foreign theories to relevant research in China, expanding the scope and scale of CDA.

\section{Practical Research}

Theoretical research on CDA has laid solid foundation for the application of CDA to practical studies. Critical analysts have taken advantage of different CDA perspectives to analyze various discourses such as advertisement, institutional discourse, legal discourse, political discourse, speeches, medical discourse, literary discourse, teaching discourse, TV interviews and so forth. In recent three years, Chinese scholars in the field of linguistics and media studies have made numerous attempts in exploring the critical factors in various kinds of discourse, aiming to expose the relationship between power, discourse and ideology. The latest research findings are as follows:

$\mathrm{Xu}$ and $\mathrm{Du}$ (2009) [22] took the ideational, interpersonal and textual function of SFG as an analytical tool to compare two news reports from aspects of classification, transitivity and modality. By doing so, they intended to reveal how discourse is controlled by ideology and how ideology disguises social contradictions by seemingly objective reporting. In fact, news agencies are apt to express their inclination in accordance with the benefits of the country or party they serve, and such inclination would be presented in the news discourse. As a result, it is necessary to comprehend news reports critically to grasp the political intention of reporters.

Yang (2009) [23] claimed that the constitutionalization of legal discourse is an outstanding and typical unity of ideological practice by analyzing the inter-relation among discourse, power and ideology of legal discourse. He pointed out that discourse ideology aims to acquire or maintain power and to constitute the society. As a result, legal discourse is both a domain and a means of power competition.

Based on Halliday's SFG, Fowler's classification of modality and van Dijk's theory on ideological analysis, Yan and Zhao (2009) [24] analyzed the modality system from speeches about war and peace from John McCain and Barack Obama to reveal the manipulative and persuasive functions of modality in political discourse. The research findings show the frequent use of modality in political discourse can be served as an effective and important strategy to deliver speaker's viewpoints and ideology and to impose their standpoints on the targeted audience implicitly.

Xie and Li (2010) [25] investigated ten speeches made by the U.S. president George Bush and ten related news reports about the speeches, aiming to explore how the two media discourse implicitly influence readers in the sense of ideology in different ways. Research findings show that all the speeches and reports attempt to influence their targeted audience with their ideological inclination. Moreover, Bush put his personal emotion into his proposition and proposals, intensifying his speeches' ideological significance.

Zhang and Liu (2011) [26] pointed out that the theoretical framework of critical linguistics needs improving to stress the features of language. By analyzing and interpreting the lexical-grammatical features of certain discourse, they summarized the basic principles of social factors and ideological elements in the discourse and concluded that ideational meaning leaves some of the information aside by employing particular grammatical patterns and interpersonal meaning realizes ideological features by employing particular lexical patterns to express implicit and explicit standpoints.

Wang \& Sun (2011) [27] and Geng (2012) [28] focused on the ideological trend of NYT news reports concerning China. Wang \& Sun analyzed news reports concerning China in NYT from the perspective of nominalization and tried to figure out the ideological tendency in them. They pointed out that the frequent use of nominalization obscures the interpersonal relations, shadows the time standards, changes the focus of attention and presupposes the pragmatic effects, thus exerting a negative influence on the shaping of Chinese image in the international community. In a similar way, Geng found that NYT puts underlined ideological meanings in the reporting of issues concerning China, legalizes and naturalizes these meanings, thus damaging "Chinese image" in the long run.

$\mathrm{Wu}$ (2012) [29] revealed the inter-relations among discourse, ideology, and power by analyzing the unity of test, discourse practice and social practice of TV ads. With Fairclough's 3-D model and Halliday's functional grammar, he pointed out that TV cosmetics ads are publicizing notions of consumption, values and lifestyles while tempting people to buy their products. Therefore, TV audiences are liable to be guided by ads to accept and the values conveyed in the ads when acquiring information in ads and should be critical and cautious while appreciating ads. 
Wen (2012) [30] maintains that discourse exercises the power of knowledge, social class and institutions, so discourse participants take different strategies due to their own status and benefits in the power relations. And college students actually constitute new discourse norms in their sending SMS.

Chen (2012) [31] and Ji (2012) [32] applied CDA theories to the cultivation of students' reading abilities. Chen designed a feasible and effective critical model to teach Selected Readings from English Newspapers and Magazines based on CDA: implicit critical reading can be taught from three layers of semantics, syntax and discourse to promote students' awareness of critical reading skills. Ji first discussed the necessity of critical reading skills and then proposed an attempt to improve students' reading abilities: teachers should inform students with basic CDA concepts and guide students to read and comprehend English news in the social context; in this way, students' initiative and awareness of reading will be triggered and their reading abilities will be promoted.

Practical research on CDA studies in recent years can be classified into two categories. The first category focuses on the exploration of various English discourses, including political speeches, TV advertisements, interviews, news reports, short message and so forth, aiming to disclose the power relations and ideology hidden in the discourse. The second category attempts to put the research findings of the first category to improve the teaching of English reading in Chinese context, hoping to cultivate students' ability to read and think independently and critically.

Although all related research findings shed light on the study of "representation of reality in media", they still have limitations in the following aspects. To begin with, few studies investigate reports about a single issue during a period of time in a renowned western media. Secondly, there are no comprehensive CDA studies exploring news discourse in all three linguistic forms of vocabulary, sentence and texts. Thirdly, previous CDA studies in the linguistic circle mainly concentrate on the language, leaving the ideology concealed in the discourse aside.

\section{Summary}

CDA, both as a branch of text-linguistics and an effective tool to carry out discourse analysis, aims to disclose the relationship between discourse, power and ideology. It proves that discourse facilitates people's participation in political struggles, promotes the constitution of social reality, inter-personal relations, knowledge and belief, and facilitates social and cultural development. Based on Fairclough's CDA model and Halliday's SFG, Chinese scholars in related fields have made many attempts to apply CDA to the interpretation of diverse discourse forms and accomplished plenty of achievements.

\section{Acknowledgements}

This research was financially supported by the Shaanxi Province Social Science Fund (Grant NO. 2014J13) and the Fundamental Research Funds for Central University (Grant NO. 3102014RW0012).

\section{REFERENCES}

[1] Mills, S. Discourse: The New Critical Idiom [M]. London: Routledge, 1997.

[2] Leslie, B. \&Ernest, M. Why Critical Discourse Analysis in Literacy Research [A]. Year Book of the National Reading Conference [C]. Michigan: Texas Christian University Press, 2006: 54 .

[3] Fairclough, N. Critical Language Awareness [M]. London: Longman, 1992.

[4] van Dijk, T. A.Ideology: A Multidisciplinary Approach [M]. London: Sage, 1998.

[5] Fairclough, N.\& Clive, H. Critical Discourse Analysis: The Critical Study of Language [M]. London: Longman, 1995.

[6] Fairclough, N. Language and Power [M]. London: Longman, 2001.

[7] van Dijk, T. A. Critical Discourse Analysis [A]. In Deborah Tannen, Deborah Schiffrin \& Heidi Hamilton (Eds.).The Handbook of Discourse Analysis [C]. Oxford: Wiley-Blackwell,1999.

[8] Chen, Zhongzhu. A Survey of Critical Linguistics. Foreign Language Teaching and Research. 1995 (1).

[9] Lan, Xijun, Wang Yuanqi. A Survey of Critical Discourse Analysis Studies in China in Recent Five Years. Journal of Southwest Agricultural University(Social Science Edition). $2010(2)$.

[10] Li, Suling. Critical Discourse Analysis:Brief Review and Its Prospective Application. Shandong Foreign Language TeachingJournal. 2004 (5).

[11] Yuan, Chunming; Tian, Hailong. The English and Chinese Political Discourse: Contrastive and Critical Analysis. Journal of Tianjin University of Commerce, 2001 (2).

[12] Jiang, Xiaohong. An Effective Approach to Critical Discourse Analysis-Functional Grammar. Academic Exchange. 2003 (3).

[13] Xin, Bin. Language, Power and Ideology: Critical Linguistics. Modern Linguistics. 1996 (2).

[14] Xin, Bin. Critical Analysis of English Discourse. Journal of Sichuan International Studies University. 1997 (4).

[15] Xin, Bin. Critical Linguistics and Critical Analysis of English News. Foreign Language Teaching. 2000 (4).

[16] Xin, Bin. On the Methodology of Critical Discourse Analysis. Journal of Foreign Languages. 2002 (6). 
[17] Xin, Bin. Critical Discourse Analysis: Problems and Discussions. Journal of Foreign Languages.2004 (5).

[18] Ji, Wei. Critical Discourse Analysis and Cultivation of Critical English Reading Competence. Journal of Southwest Agricultural University (Social Science Edition). 2012 (11).

[19] Dai, Weihua; Chen, Yujun. Theories and Methods of Critical Discourse Analysis. Foreign Languages Research. 2004 (4).

[20] Li, Na; Zhang, Faxiang. Recapitulation of Critical Discourse Analysis. Journal of Zhengzhou Institute of Aeronautical Industry Management (Social Science Edition). 2007 (4).

[21] Zhang, Delu. On A Synthetic Theoretical Framework for Multimodal Discourse Analysis. Foreign Languages in China. 2009 (1).

[22] Xu, Liqin; Du, Juan. News Analysis from the Perspective of Critical Discourse Analysis. Foreign Language Education. 2009 (4).

[23] Yang, Dexiang. Critical Discourse Analysis of Power Awareness in Legal Discourse. Journal of Ningxia University (Humanities and Social Sciences Edition). 2009 (9).

[24] Yan, Shiqing; Zhao, Xia. Modality in Political Discourse and Its Critical Discourse Analysis. Journal of Suzhou University (Philosophy \& Social Science). 2009 (2).
[25] Xie, Huiqin; Li, Liutao. Critical Discourse Analysis of News Reports. Journal of Shayang Teachers College. 2010 (3).

[26] Zhang, Delu; Liu, Xiuli. Lexicogrammar in Critical Discourse Analysis. Journal of Ocean University of China (Social Sciences Edition). 2011 (2).

[27] Wang, Lin; Sun, Zhixiang. Ideological Inclination in China-Related News in New York Times. Journalism Lover. 2011 (11).

[28] Geng, Fang. Ideological Inclination in China-Related News in New York Times - A Perspective From Critical Discourse Analysis. Modern Communications. 2012 (7).

[29] Wu, Weijun. A Critical Discourse Analysis of TV Advertisements. Journalism Lover. 2012 (2).

[30] Wen, Renbai. Construction of Discourse Norm: A Critical Discourse Analysis of SMS among Chinese College Students. Foreign Language Education. 2012 (3).

[31] Chen, Lingjun. An Empirical Study of Application of Critical Discourse Analysis Theories to News Reading Course [J]. Journal of Tianjin Foreign Studies University. 2012 (9).

[32] Ji, Yuhua. Critical Discourse Analysis: Theories and Methods. Journal of Xiamen University (Arts \&Social Sciences). 2001 (3). 